\title{
LED-Lamp Design for Renewable Energy-Based DC House Application
}

\author{
Rini Nur Hasanah ${ }^{1}$, Yosi Dwi Handari ${ }^{2}$, Soeprapto ${ }^{3}$, Taufik ${ }^{4}$ \\ 1,2,3Electrical Engineering Department, Brawijaya University, Indonesia \\ ${ }^{4}$ Electrical Engineering Department, Cal Poly State University, United State
}

\begin{abstract}
Article Info
Article history:

Received May 19, 2018

Revised Jul 22, 2018

Accepted Aug 9, 2018

\section{Keyword:}

DC-DC buck converter

DC house

LED bulb

ABSTRACT

This paper describes the design of an LED lamp to be used in a DC house being supplied using a renewable energy source or in a DC Smart Grid. LED lamps are widely known for its low-electricity consumption. The DC house application is becoming more and more popular due to its advantage of using DC generated electricity, for example from a solar photovoltaic system, directly without having to invert it into AC voltage. However, LED needs a driver to activate and control it. Its mounting also needs certain precaution to anticipate the high heat from the LED. An appropriate heatsink is required before activating the LED. The laboratory results indicate that a 3-watt LED bulb lamp can produce an efficiency up to $93.16 \%$ with luminous efficacy $82.29 \mathrm{~lm} / \mathrm{W}$. These results prove that an LED bulb consumes less energy and can give an optimal brightness.
\end{abstract}

LED driver

Renewable energy resources
Copyright $(2018$ Institute of Advanced Engineering and Science. All rights reserved.

\section{Corresponding Author:}

Rini Nur Hasanah

Electrical Engineering Department, Brawijaya University,

MT Haryono Street 167 Malang 65145, Indonesia.

e-mail: rini.hasanah@ub.ac.id

\section{INTRODUCTION}

DC house application has been winning more and more interests to boost the use of electricity directly from renewable energy sources without having to involve many inverting power electronic devices [1]. It offers the possibility to benefit low-power low-voltage generated electricity without passing the AC power transmission and distribution systems [2]. Being integrated to form a DC microgrid system, it has been proven to cause significantly less power losses being compared to its AC counterpart systems [3-4]. The DC house system can take the benefit from the DC generation system [3-6]. It also provides its energy need itself through the conversion of various renewable energy sources such as photovoltaic, hydro, wind, and even human labor $[2,7]$.

The most important equipment which must be available in a house is the lighting system. LEDbased lighting has been recently known as very efficient and of low-energy consumption. A LED is working on direct current (DC) voltage, so it is very suitable as the load in a DC-house. As the mains current is normally an alternating current (AC) at much higher voltage than the LED can accept, certain circuitry is sometimes needed to convert the mains AC into DC at the correct voltage, although some low-voltage LEDs are also available in the market. A LED light design being developed in [7] produced light bulb's efficiency until $85.63 \%$ with a voltage range between $24 \mathrm{~V}-72 \mathrm{~V}$ and power consumption of 13,44 watts. It also produced enough illumination levels for lighting at home. This paper presents a design of LED-lamp to be used in a DC house being supplied using a renewable energy source or in a DC Smart Grid [7, 8]. 


\section{RESEARCH METHOD}

\subsection{House System}

The DC house system gains its interest due to the concern to use electricity at low cost [9]. A DC house can be supplied by electricity resulted from various renewable energy resources available surrounding the house [2,7]. An example of the basic design of a DC-house is shown in Figure 1.

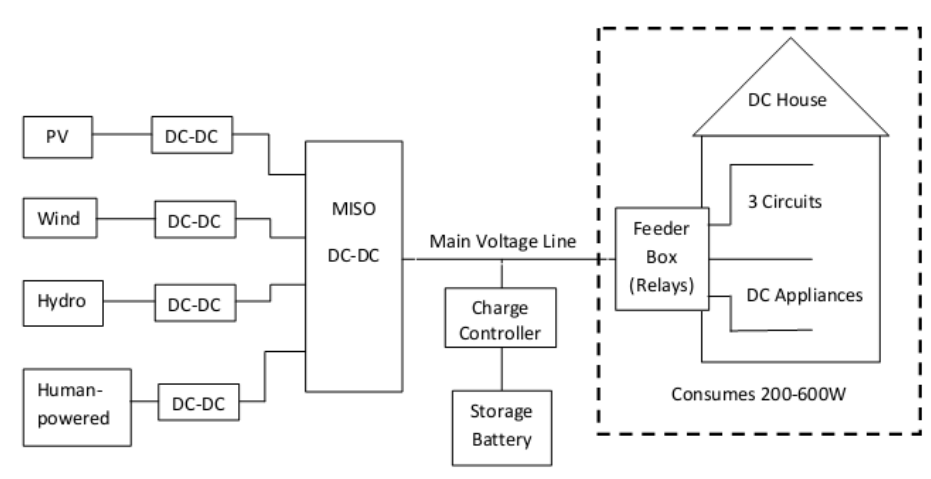

Figure 1. The basic design of a DC-house

As shown in Figure 1, there are four renewable energy resources as the source of electricity. The DC generated electricity is connected to each of the boosting DC-DC converters to raise the voltage level of generation, for example from $12 \mathrm{~V}$ to $24 \mathrm{~V}$ [9]. It then becomes the input of a Multiple-Input Single-Output (MISO) DC-DC converter which is then connected to the Main Voltage Line of a Feeder Box (Relays). The main voltage line is connected through a charge controller to a battery storage with a certain capacity. The feeder box comprises relays, including multiple circuit breakers and fuse to control the distribution of energy and to protect against the ground faults on the DC [9].

\subsection{LED (Light-Emitting Diode)}

Light-emitting diode, or known as LED is a two-lead semiconductor light source in the form of a p-n junction diode emitting light when activated. Commonly, it does not emit light in all directions, although omnidirectional lamps are becoming more popular. The LED design considered in this paper is based on the latest LED lighting technology, the high-power LED as shown in Figure 2, which is capable of producing high light intensity (up to 80-100W/lumen) with small power consumption. The LED requires a certain driver to turn on and generates considerable heat (high heat), which is not coming from the light but from the back part of the LED. Consequently, an appropriate heatsink is required.
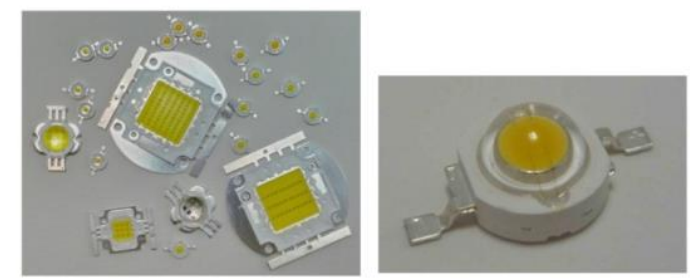

Figure 2. High-power LED

\subsection{LED-Lamp Design}

An overview of the general arrangement of an LED light bulb in producing light is given in Figure 3. As seen, the VIN and GND are supplied directly from the 48V DC-bus voltage of the DC house. They are connected directly to the LED driver which should be designed based on the desired LED-Lamp design. The positive output side of the LED driver is connected to the positive input side of the LED Array, 
whereas the negative output of the LED Array is fed into the negative side of the LED driver LED_N. Based on this arrangement the LED will produce light.

The block diagram of the LED driver LT3590 is given in Figure 4. It is a high voltage current-mode buck-mode LED driver which is able to generate a constant current to the LED circuit with a voltage up to $40 \mathrm{~V}$. It has internal compensation feature, a $55 \mathrm{~V}$ internal power switch and a $55 \mathrm{~V}$ internal Schottky diode which allow the DC current up to 50mA with an efficiency up to $91 \%$ [10].

The LT3590 has a 3.3V linear regulator onboard with an ability to supply external device up to $1 \mathrm{~mA}$. The $3.3 \mathrm{~V}$ regulator remains available even when at the shutdown state. This feature can be used to power-up external LT3590 controller which can control the LED current resulted by activating the CTRL pin. Alternatively, the output pin regulator (VREG) may be connected directly to the CTRL pin (Pin 5). When the CTRL pin is given the voltage over $150 \mathrm{mV}$, the oscillator, PWM comparator, and the error amplifier will be active. The LT3590 using the buck-mode converter to regulate the output voltage to the LED voltage levels required to match the required current [10].

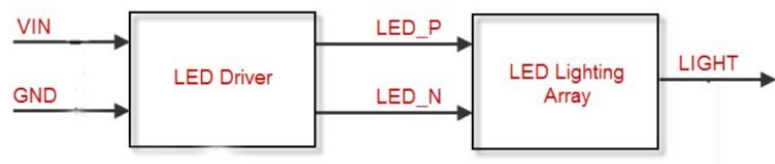

Figure 3. Block diagram of the Bulb Circuit

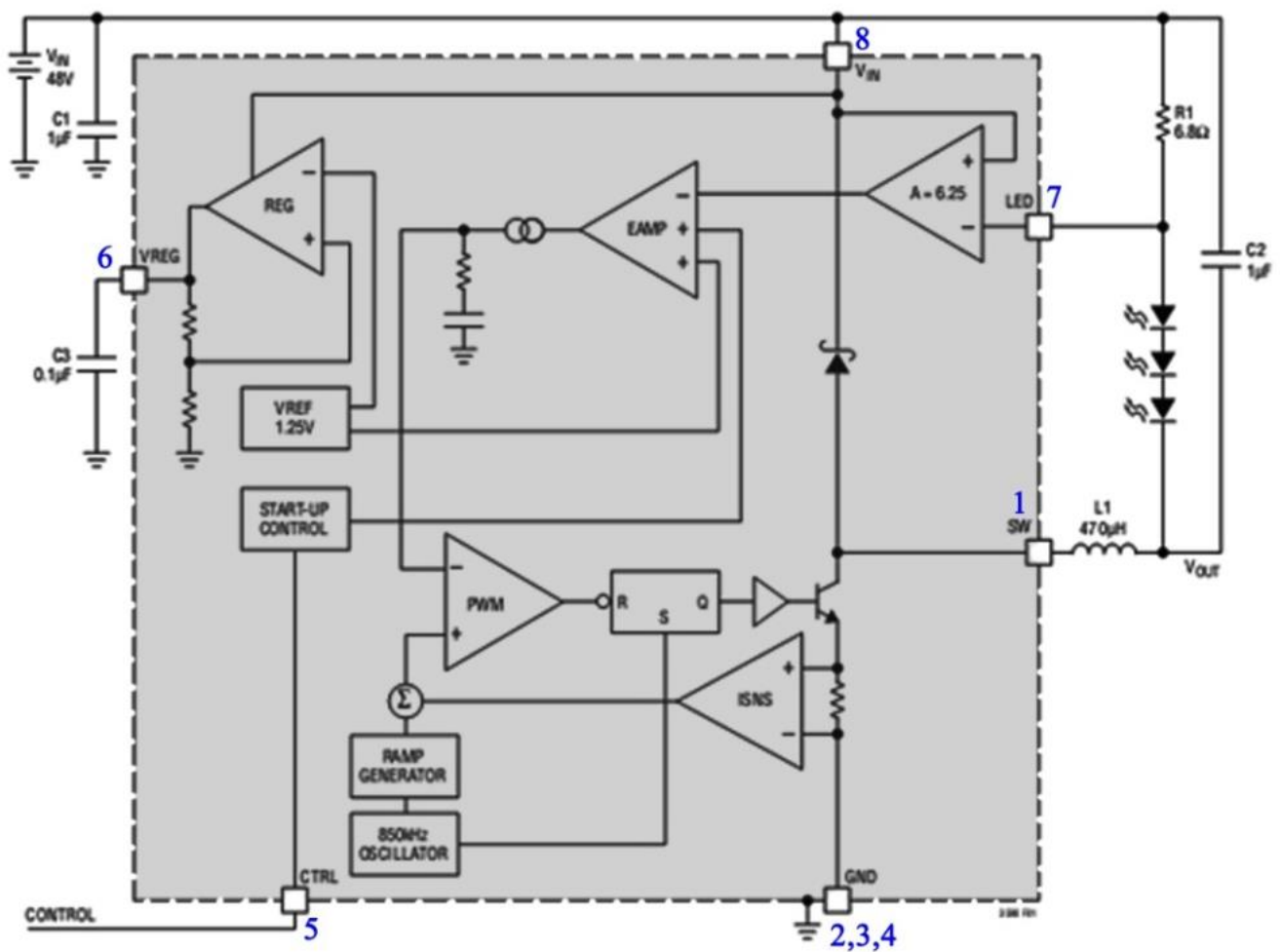

Figure 4. The block diagram of the LED driver LT3590

\subsection{LED Array}

The LED design should match with the standard of the lamp dimensions to be adopted. Thus, the design of the LED arrays must fit well with the dimensions of the lamp. In this paper, the LED bulb housing has been customized from that of the existing Royal 12VDC LED bulb lamp, as shown in Figure 5. The used LEDs are made by Epistar [11]. The Epistar LED lamp produces the luminous flux of about $400 \mathrm{~lm}$, containing 5 LEDs, giving a luminous flux of $80 \mathrm{~lm}$ each. As the designed bulb lamb in this paper uses three LEDs, it should produce $240 \mathrm{~lm}$ and be arranged in a triangular form on the top of a Metal-Core PCB 
(MCPCB) before being attached to an aluminum heatsink. The final design of this LEDs array is shown in Figure 6.

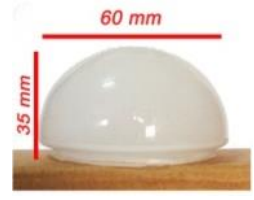

(a)

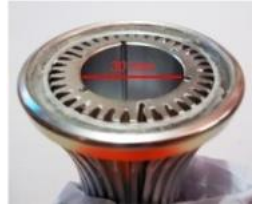

(b)

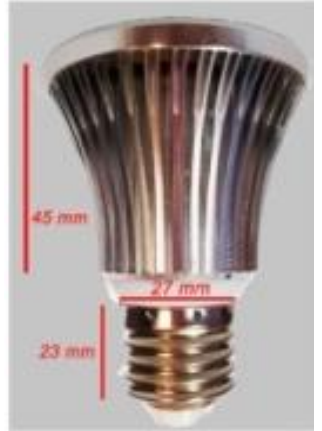

(c)

Figure 5. Bulb Mechanics, (a) Light Diffuser, (b) Aluminum Heatsink's dimension, (c) Aluminum Heatsink and E27 Screw Base
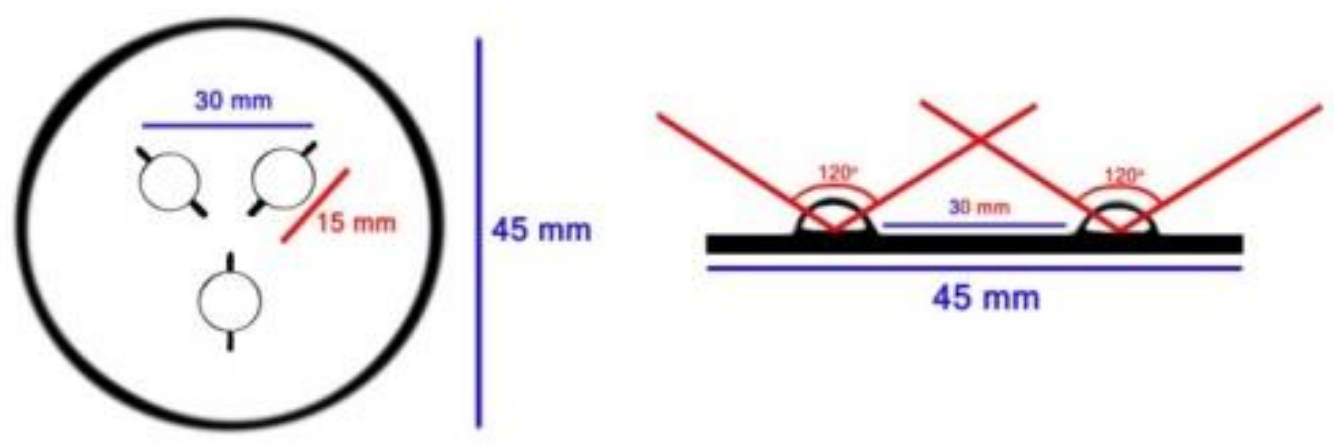

(a)

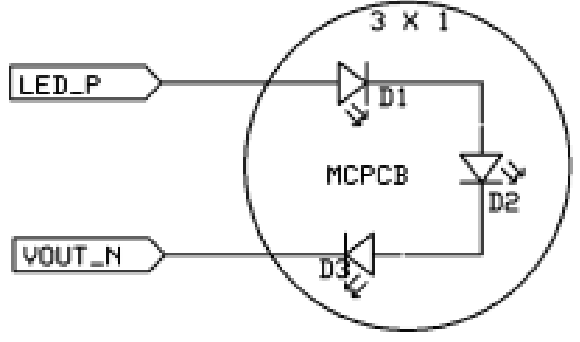

(b)

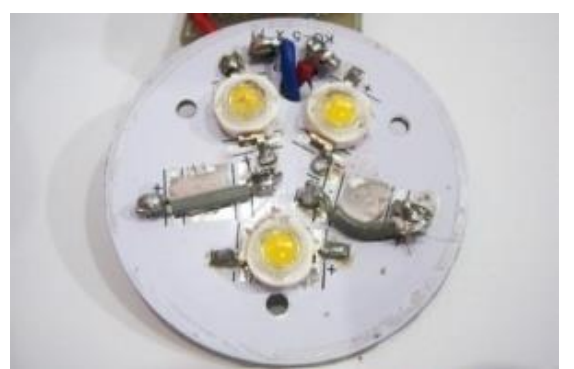

(c)

Figure 6. The placement of the LEDs on the MCPCB of a used Royal LED, (a) the LED distance design, (b) schematic design, (c) physical design

In order to form a triangular formation, the LEDs position and the distance between them need to be calculated. It is aimed to make the LED lamp be able to spread the light equally. The distance is determined based on the size of the LED, which is about $15 \mathrm{~mm}$. The position has been made to form an equilateral triangle to produce a viewing angle of $120 \mathrm{o}$, giving a distance of $30 \mathrm{~mm}$ between LEDs. This is the best distance with respect to the MCPCB dimension, in order for the light bulb to produce the maximum light intensity. However, in order not to cause the light out in one spot only, a light diffuser to spread the beam is required (Figure 5). 


\subsection{LED Driver}

The LED driver design shown in Figure 7 comprises the following components [12]:

a. $6,8 \Omega$ resistor providing the current ILED $30 \mathrm{~mA}$

b. $470 \mu \mathrm{H}$ inductor to make the constant DC current

c. $1 \mu \mathrm{F} 50 \mathrm{~V}$ polar capacitor $(\mathrm{C} 1)$ as the output capacitor to regulate the $\mathrm{VIN}=48 \mathrm{~V}$

d. $1 \mu \mathrm{F}$ nonpolar capacitor $(\mathrm{C} 2)$ as the regulator capacitor in the LED array circuit

e. $0,1 \mu \mathrm{F}$ nonpolar capacitor $(\mathrm{C} 3)$ as the regulator capacitor which is connected to pin VREG whose voltage is regulated.

\section{RESULTS AND ANALYSIS}

\subsection{Simulation Results of the Current $I_{L E D}$ as a function of time}

The graph of the current ILED as a function of time $t$ obtained using the LTSpice simulation program is given in Figure 8. It is the LED current flowing in D1, in Figure 7. As the three LEDs are connected in series, the current graphs of the D2 and D3 are the same. The input current is determined by the resistance of the installed resistor R1, as seen in Figure 7. The resulted input power PIN can be seen in Figure 9. The efficiency can be obtained using the data of VIN, IIN, and VOUT, IOUT in Figure 9. It gives an efficiency of the bulb higher than $80 \%$, which is $97.51 \%$. The overall simulation results of the DC LED light bulb are presented in Table 1 .

\subsection{The Resulted Layout of 2-Layer PCB Custom Design}

The 2-Layer PCB custom design has been obtained using two steps in designing the PCB LED Driver. The first step is creating a circuit's schematic, which has been done using ExpressSCH, as shown in Figure 10. The next step is creating a PCB prototype design using ExpressPCB - a PCB design application which can be used for creating 2-layer until 4-layer PCB prototype designs. The resulted 2-layer PCB design is shown in Figure 11, containing the schematic design as well as the physical design of each layer.

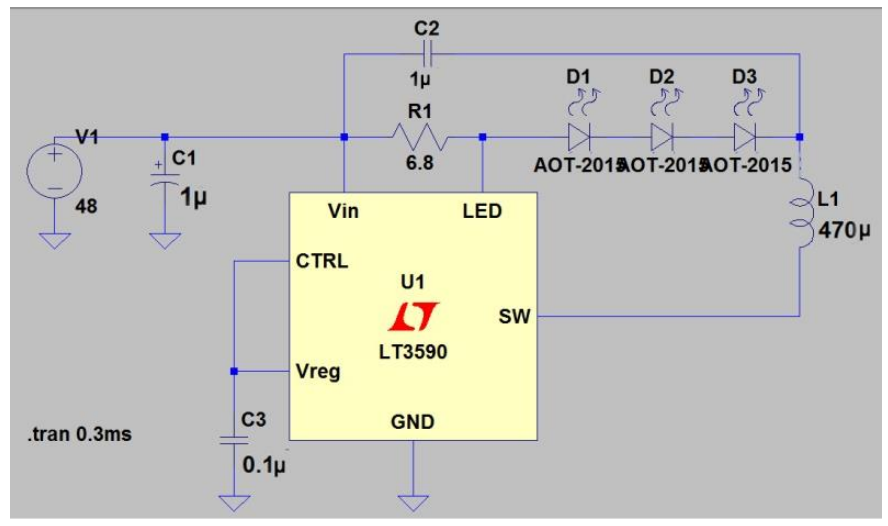

Figure 7. LED Driver Schematic at 48V Buck-Mode LED Driver

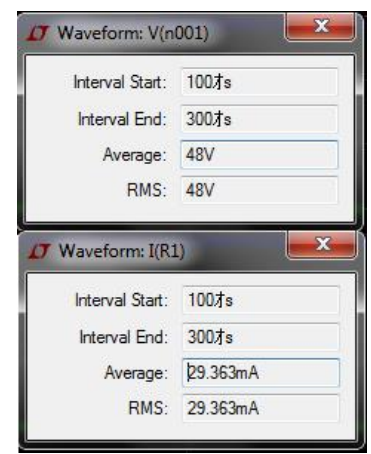

(a)

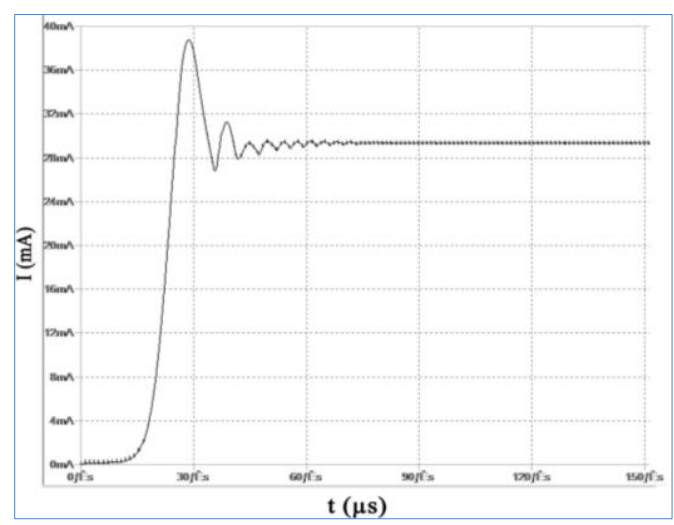

Figure 8. The ILED current graph as a function of time

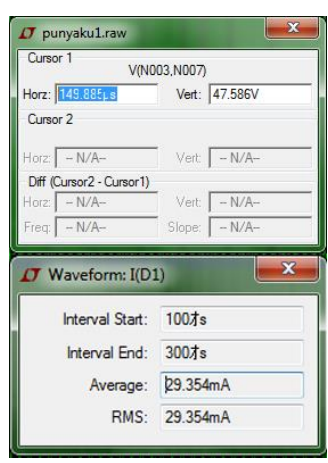

(b)

Figure 9. The resulted values of (a) VIN and IIN (b) VOUT and IOUT in the LTSpice Simulation Software 
Table 1. Simulation Results of the DC LED Light Bulb

\begin{tabular}{cc}
\hline Parameter & Specification \\
\hline Bus Voltage (Simulation):VIN & $48 \mathrm{~V}$ \\
Output Voltage in Buck-Mode & $0 \mathrm{~V}-12 \mathrm{~V}$ \\
:VLED & $97.51 \%$ \\
Efficiency at Full Load* & $4.189 \mathrm{~W}$ \\
Power Consumption* & 3 \\
LEDs in Series & Cool White \\
Color Temperature & $85 \mathrm{oC}$ \\
Maximum Temperature & Up to 2401m \\
Junction & $3.25 \mathrm{~V}$ \\
Luminous Flux & $350 \mathrm{~mA}$ \\
Maximum Forward Voltage & Yes \\
Maximum LED's Forward & Yes \\
Current & \\
Constant Voltage Regulation & \\
Constant Current Regulation & *Test Result using AOT-2005 (x3) \\
\hline
\end{tabular}

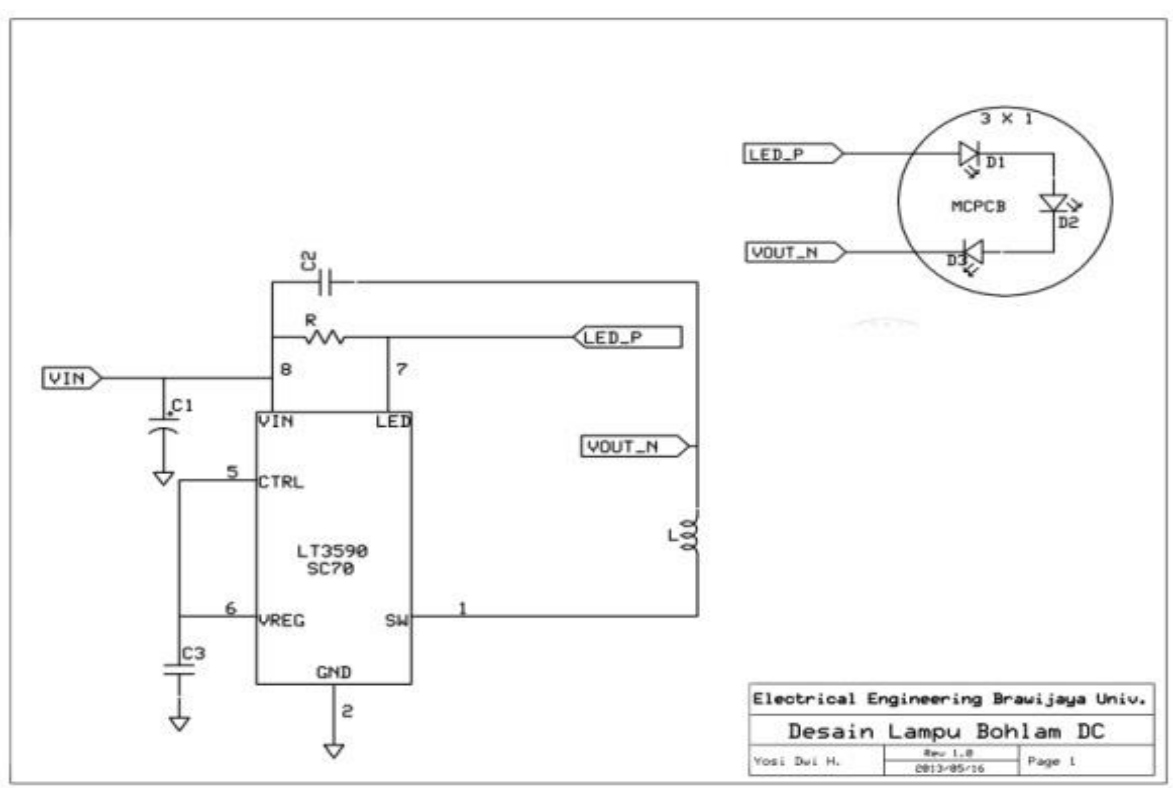

Figure 10. The schematic design of the DC Light Bulb using ExpressSCH

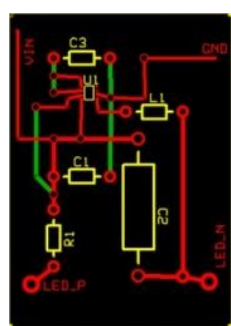

(a)

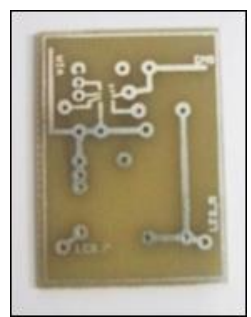

(b)

First layer

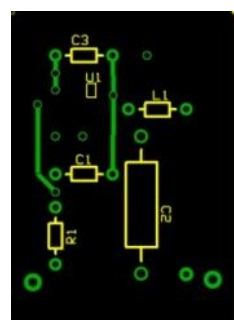

(a)

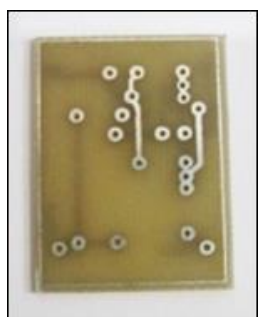

(b)

Figure 11. The 2-layer PCB design, (a) schematic design, (b) physical design

The obtained PCB with the dimension of $3.5 \times 2.5 \mathrm{~cm}$ were then ready to be mounted with the required components as determined in the datasheet of LTSpice, as seen in Figure 13. 


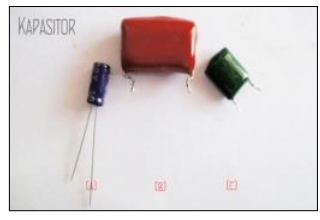

(a)

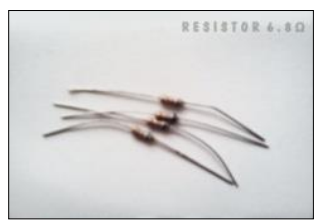

(b)

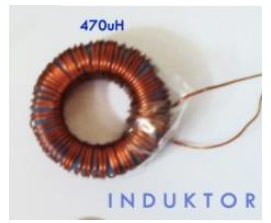

(c)

Figure 13. Components used for outer circuit design, (1) Capacitors (a) Polar $1 \mu \mathrm{F}$ (b) Nonpolar $1 \mu \mathrm{F}$ (c) Nonpolar 0.1 $\mathrm{F}$; (2) Resistor; (3) Inductor

\subsection{The Efficiency Test Results}

The efficiency has been known from the results of measurements performed using a multimeter to get ILED, VLED, with the given input voltage VIN range of $0 \mathrm{~V}-48 \mathrm{~V}$, as seen in Table 3.

Table 3. Data of measurement results on the DC LED Bulb

\begin{tabular}{|c|c|c|c|c|c|c|c|c|}
\hline $\mathrm{V}_{\mathrm{IN}}(\mathrm{V})$ & $\mathrm{I}_{\mathrm{IN}}(\mathrm{mA})$ & $\mathrm{P}_{\mathrm{IN}}(\mathrm{W})$ & $\mathrm{V}_{\text {LED }}(\mathrm{V})$ & $\mathrm{I}_{\mathrm{LED}}(\mathrm{mA})$ & $\mathrm{V}_{\text {OUT }}(\mathrm{V})$ & $\mathrm{P}_{\text {OUT }}(\mathrm{W})$ & Efficiency & LED State \\
\hline 0 & 0 & 0 & 0 & 0 & 0 & 0 & - & Off \\
\hline 6 & 0.6 & 0.0108 & 1.3 & 0 & 4.3 & 0 & 0 & Off \\
\hline 12 & 122 & 4.3920 & 8.5 & 29.9 & 3.9 & 0.3498 & 7.9652 & On \\
\hline 18 & 70.8 & 3.8232 & 8.5 & 29.9 & 9.7 & 0.8701 & 22.7582 & On \\
\hline 24 & 52.3 & 3.7656 & 8.5 & 30 & 17.7 & 1.5930 & 42.3040 & On \\
\hline 30 & 40.6 & 3.6540 & 8.5 & 30 & 23.8 & 2.1420 & 58.6207 & On \\
\hline 36 & 35.8 & 3.8664 & 8.5 & 30 & 29 & 2.6100 & 67.5047 & On \\
\hline 42 & 30.9 & 3.8934 & 8.5 & 30 & 32.9 & 2.9610 & 76.0518 & On \\
\hline 48 & 26.5 & 3.8160 & 8.5 & 30 & 39.6 & 3.5640 & 93.3962 & On \\
\hline
\end{tabular}

As seen from Table 3, the LED driver LT3590 could operate optimally, being indicated by the value of LED voltage VLED dan current ILED which were of constant values although the input voltage VIN had been increased up to $48 \mathrm{~V}$. As the LT3590 is a Buck-Mode LED Driver, the input voltage can be decreased and regulated. When the voltage started to be constant, the input current IIN started to decrease. When the input current to the lamp is lower, higher will be the resulted efficiency. The calculated efficiency of the LED lamp was about $93.39 \%$ at $48 \mathrm{~V}$, which is higher than $80 \%$ and more approaching the result of simulation. Figure 14 indicates the comparison of VLED as a function of VIN and ILED as a function of VIN.

\subsection{The Temperature Test Results}

The temperature measurement of the DC light bulb has been undertaken using an infrared thermometer, which is a laser-based temperature measuring device, as seen in Figure 15. The considered maximum junction temperature of the LED was $85^{\circ} \mathrm{C}$ as suggested in [11]. In order for a LED to have a long life, the measured temperature should be less than the maximum junction temperature. The measurement results are displayed in Table 4.

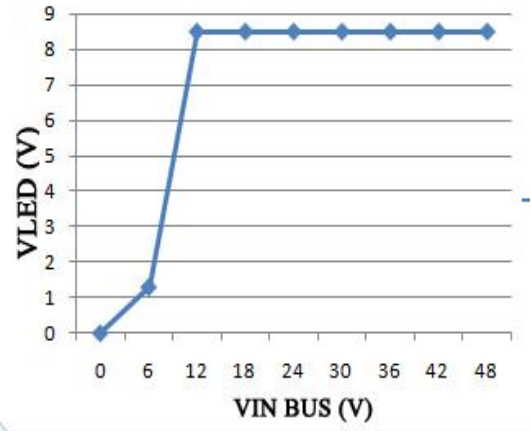

(a)

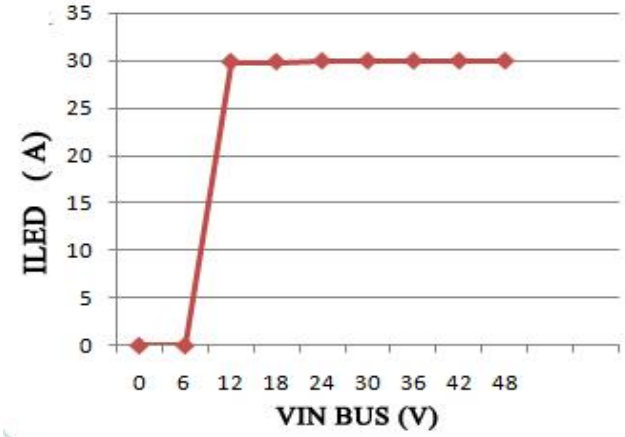

(b)

Figure 14. The curves (a) VLED-VIN, (b) ILED-VIN 


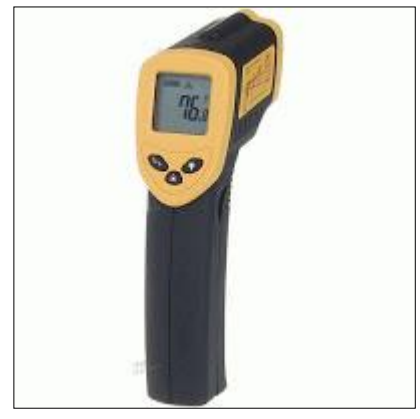

Figure 15. Infrared Thermometer

Table 4. Measurement Results of Temperature on the PCB and LED Arrays using an Infrared Thermometer

\begin{tabular}{ccccccc}
\hline \multirow{2}{*}{$\begin{array}{c}\text { t } \\
\text { minute) }\end{array}$} & \multicolumn{7}{c}{ Temperature $\left({ }^{\circ} \mathrm{C}\right)$} \\
\cline { 2 - 7 } & PCB & LED Array & PCB & LED Array & PCB & LED Array \\
\hline 0 & 28 & 28.3 & 27 & 28 & 28 & 28.4 \\
5 & 29 & 31.9 & 27.7 & 32.1 & 28.9 & 34.3 \\
10 & 31 & 35.2 & 28.2 & 34.5 & 31 & 33.6 \\
15 & 33 & 40.3 & 28.6 & 41.1 & 32 & 43.3 \\
20 & 35 & 43 & 29 & 42.1 & 33.5 & 41.4 \\
25 & 36.4 & 46.6 & 29.4 & 45 & 35 & 47.1 \\
30 & 35.8 & 51 & 31 & 50.5 & 35.4 & 50.2 \\
35 & 35.9 & 53.5 & 32.1 & 55.9 & 35.9 & 55.1 \\
40 & 36 & 55.3 & 34.5 & 58.3 & 36 & 58.1 \\
45 & 36 & 58.6 & 34.9 & 59.9 & 36.1 & 60 \\
50 & 36 & 61.3 & 35.5 & 61.3 & 36.6 & 61.6 \\
55 & 36 & 61.4 & 35.5 & 61.7 & 37 & 61.8 \\
60 & 36 & 61.4 & 35.6 & 61.8 & 36.9 & 61.8 \\
\hline
\end{tabular}

As seen in Table 4, all the measured temperatures are below $85^{\circ} \mathrm{C}$. It means that the resulted design is ensured to be safe and long-lived. However, from the observation done it could be known that the placement of aluminum heatsink mounted on the MCPCB could have still been improved, which would bring about cooler temperatures than what had been measured.

\subsection{Lumination Measurement Results}

The results of calculation and measurement of the light intensity are given in Table 5. The lumination has been measured using a lux meter. The obtained data are then used to calculate the luminous efficacy by using some following formulas.

$$
\begin{aligned}
& \text { The area of a sphere: } \\
& \mathrm{A}_{\text {SPHERE }}=4 \pi \mathrm{r}^{2} \\
& 1 \text { lux }=\frac{\text { lumens }}{\mathrm{m}^{2}} \\
& \text { luminous efficacy }=\frac{\text { lumens }}{\mathrm{P}_{\text {in }}} \\
& \text { Luminous flux total on a working place (lumen): } \quad \mathrm{F}_{\text {total }}=\frac{\mathrm{E} \times \mathrm{A}}{\mathrm{k}_{\mathrm{p}} \times \mathrm{k}_{\mathrm{d}}}
\end{aligned}
$$

where $\mathrm{E}$ is the lumination (lux), A is the working area, $\mathrm{kp}$ is the utility factor, $\mathrm{kd}$ is the light loss coefficient. 
Table 5. The Results of Calculation and Measurement of the Light Intensity

\begin{tabular}{ccccccccc}
\hline & $\begin{array}{c}\text { Distance } \\
(\mathrm{m})\end{array}$ & $\begin{array}{c}\text { Lumination } \\
(\mathrm{lux})\end{array}$ & $\mathrm{V}_{\mathrm{IN}}(\mathrm{V})$ & $\mathrm{I}_{\mathrm{IN}}(\mathrm{mA})$ & $\mathrm{P}_{\mathrm{IN}}(\mathrm{W})$ & $\begin{array}{c}\mathrm{A}_{\text {SPHERE }} \\
\left(\mathrm{m}^{2}\right)\end{array}$ & $\begin{array}{c}\text { Luminous Flux } \\
(\mathrm{lm})\end{array}$ & $\begin{array}{c}\text { Luminous Efficacity } \\
(\mathrm{lm} / \mathrm{W})\end{array}$ \\
\hline 1 & 1 & 25 & 0 & 0 & 0 & 12.56 & 314.00 & 0.00 \\
2 & 1 & 25 & 6 & 0.6 & 0.0108 & 12.56 & 314.00 & 0.00 \\
3 & 1 & 25 & 12 & 122 & 4.392 & 12.56 & 314.00 & 71.49 \\
4 & 1 & 25 & 18 & 70.8 & 3.8232 & 12.56 & 314.00 & 82.13 \\
5 & 1 & 25 & 24 & 52.3 & 3.7656 & 12.56 & 314.00 & 83.39 \\
6 & 1 & 25 & 30 & 40.6 & 3.654 & 12.56 & 314.00 & 85.93 \\
7 & 1 & 25 & 36 & 35.8 & 3.8664 & 12.56 & 314.00 & 81.21 \\
8 & 1 & 25 & 42 & 30.9 & 3.8934 & 12.56 & 314.00 & 80.65 \\
9 & 1 & 25 & 48 & 26.5 & 3.816 & 12.56 & 314.00 & 82.29 \\
\hline
\end{tabular}

By determining the $\mathrm{F}_{\text {total }}$ as 240 lumens as the luminous flux specified during the beginning of the design for 3 LEDs, the lumination of about 100 lux with light losses coefficient of 0.8 [13], and utilization factor of 0.5 [14], the area of $0.96 \mathrm{~m} 2$ has been obtained. By assuming a rectangular area, it has been approximated to have a side of 1 meter, giving a lumination of 25 lux as displayed in Table 6 . The distance between the lamp and luxmeter has been obtained as $100 \mathrm{~cm}$ using Eq. 4. The obtained result of lumination measurement at the distance of $100 \mathrm{~cm}$ is 25 lux. Based on these data and using Eqs. 1-3, the luminous flux of 314 lumens and a luminous efficacy about 82.29 lumens/W at a voltage of $48 \mathrm{~V}$ have been obtained. It indicates that the resulted LED light bulb meets the minimum criteria for indoor lighting needs at home.

\subsection{Comparison of Simulation Results and Testing Results}

The comparison of complete simulation and measurement results is given in Table 6. In general it indicates the close concordance between the simulation and measurement results. The characteristic graphs of the buck-mode LED driver LT3590 obtained from simulation and measurement are shown in Figure 16. As indicated, both of them show the similar shape of graphs of the voltage through the LED bulb lamp with the maximum value of about $48 \mathrm{~V}$.

Table 6. Comparison of Simulation Result and Testing Result

\begin{tabular}{lcc}
\hline \multicolumn{1}{c}{ Parameter } & Simulation result & Testing result \\
\hline Range Input Voltage & $12 \mathrm{~V}-48 \mathrm{~V}$ & $12 \mathrm{~V}-48 \mathrm{~V}$ \\
LED Voltage (VLED) & $8.645 \mathrm{~V}$ & $8.5 \mathrm{~V}$ \\
Efficiency at Full Load & $97.51 \%$ & $93.39 \%$ \\
Power Consumption & $4.189 \mathrm{~W}$ & $3.86 \mathrm{~W}$ \\
LED Manufacturer & AOT & EPISTAR \\
LED in Series & 3 & 3 \\
Luminous Efficacy & $801 \mathrm{~m} / \mathrm{W}$ & $82.29 \mathrm{~lm} / \mathrm{W}$ \\
Luminous Flux & $240 \mathrm{~lm}$ & $314 \mathrm{lumen}$ \\
Maximum Current & $350 \mathrm{~mA}$ & $30 \mathrm{~mA}$ \\
Maximum Temperature & $85 \mathrm{oC}$ & $61.8 \mathrm{oC}$ \\
Constant Current Regulation & Yes & Yes \\
Constant Voltage Regulation & Yes & Yes \\
\hline
\end{tabular}

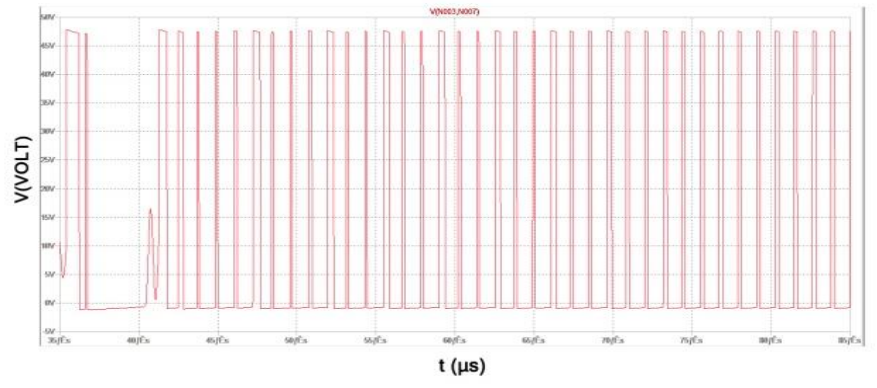

(a)

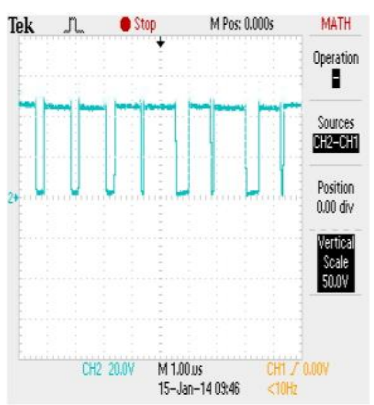

(b)

Figure 16. The regulated voltage waveform of the LED-Lamp, (a) simulation result, (b) testing result

\section{CONCLUSION}

A LED lamp with low-power consumption and high efficiency has been designed and realized. It is potential to be used in a DC house being supplied using a renewable energy source or in a DC Smart Grid. 
The experiment result of the designed LED bulb efficiency was relatively close to the results of simulation. The LED lamp could work properly on a DC-house bus voltage of 48VDC. The experiment results of luminous flux and luminous efficacy indicate that the obtained LED lamp design meet the criteria of lighting a room. The heat produced on the design could still be evacuated well through the aluminum heatsink used even though its mounting on the related MCPCB still was not perfect.

\section{ACKNOWLEDGEMENTS}

The authors would like to thanks the Power System Engineering and Energy Management Research Group (PseemRG) and the International Scientific Publication Office of Universitas Brawijaya, Indonesia, for enabling the dissemination of this research results

\section{REFERENCES}

[1] Techakittiroj K, Patumtaewapibal S, Wongpaibool V, Threevithayanon W., "Roadmap for implementation of DC system in future houses," 2008 13th International Conference on Harmonics and Quality of Power. 2008, pp. 1-5.

[2] Taufik, Muscarella M., "Development of DC house prototypes as demonstration sites for an alternate solution to rural electrification," 2016 6th International Annual Engineering Seminar (InAES). 2016, pp. 262-265.

[3] Kakigano H, Nomura M, Ise T., "Loss evaluation of DC distribution for residential houses compared with AC system," The 2010 International Power Electronics Conference - ECCE ASIA. 2010, pp. 480-486.

[4] Kimura N, Morizane T, Omori H., "Power management unit for DC feeder (DC Smart House)," 2012 International Conference on Renewable Energy Research and Applications (ICRERA). 2012, pp. 1-5.

[5] Mansur TMNT, Baharudin NH, Ali R., "Optimal sizing and economic analysis of self-consumed solar PV system for a fully DC residential house," 2017 IEEE 4th International Conference on Smart Instrumentation, Measurement and Application (ICSIMA). 2017, pp. 1-5.

[6] Kakigano H, Miura Y, Ise T., "Configuration and control of a DC microgrid for residential houses," 2009 Transmission \& Distribution Conference \& Exposition: Asia and Pacific. 2009, pp. 1-4.

[7] Liang K., "Design of DC Light Bulb for DC House Project," Thesis project. San Luis Obispo, CA: Cal Poly State University; 2012.

[8] Amin M, Arafat Y, Lundberg S, Mangold S., "An efficient appliance for low voltage DC house," 2011 IEEE Electrical Power and Energy Conference. 2011, pp. 334-339.

[9] Cabaj M., "DC House Model Design and Construction," Senior project. San Luis Obispo, CA:Cal Poly State University; 2012.

[10] Navabi MJ., "Efficient 48V Buck Mode LED Driver Delivers 50mA," Linear Technology Magazine. January, 2008. http://www.linear.com.

[11] Epistar Co. EPISTAR LAB Launched a New Platform to Achieve 3.0V White LED Chip at 1A Operation. October 2011. http://www.epistar.com.tw/_english/04_pr/02_detail.php?SID=29

[12] Linear Technology. LT3590, 48V Buck Mode LED Driver in SC70 and $2 \mathrm{~mm}$ x $2 \mathrm{~mm}$ DFN Datasheet. http://www.linear.com.

[13] BSN. Energy Conservation in a Lighting System (in Bahasa Indonesia). Indonesian National Standardization Board. Jakarta: 2001

[14] Muhaimin., "Lighting Technology (in Bahasa Indonesia)," Bandung: PT.Refika Aditama; 2001. 